\title{
CORRELAÇÃO DO P NO SISTEMA SOLO-PLANTA-ANIMAL EM PASTAGEM NATURAL NA REGIÃO DA CAMPANHA-RS
}

\author{
CORRELATION OF THE PHOSPHORUS IN THE SYSTEM SOIL-PLANT-ANIMAL IN \\ NATURAL PASTURE IN THE REGION OF CAMPANHA-RS
}

Santos, B.R.C. dos $^{1}$, Alfaya, H. ${ }^{2}$, Dias, A.E.A. ${ }^{3}$ e Silva, J.B. da ${ }^{2}$

${ }^{1} E$ mbrapa Semiárido. BR 428. Km 152. Zona Rural. Caixa Postal 23. Petrolina, PE. CEP 56302-970. Brasil. betina.cunha@cpatsa.embrapa.br

${ }^{2}$ Universidade Federal de Pelotas. UFPEL/FAEM. Campus Universitário, s/n. CEP 96010-900. Pelotas-RS. Brasil.

${ }^{3}$ Embrapa Amapá. CPAFAP. Rodovia Kubitschek, km 5, 2600. CEP 68903-419. Macapá. AP. Brasil.

\section{PalaVRAS CHAVES ADICIONAIS}

Absorção. Bovinos. Minerais. Soro sangüíneo.

\section{RESUMO}

Um estudo foi realizado para determinar a correlação do $\mathrm{P}$ no sistema solo-planta-animal com características da paisagem e qualidade da forragem em três tipos de solo não perturbados, localizados na região da Campanha-RS. Efetuouse a amostragem em áreas sobre os solos Neossolo Regolítico eutrófico (RLe), Argissolo BrunoAcinzentado (ABA) e Planossolo Háplico eutrófico $(\mathrm{PHe})$ durante um ano. A correlação linear entre $\mathrm{P}$ no solo $\times \mathrm{P}$ na planta apresentou significância no outono $(p<0,01)$ e no inverno $(p<0,05)$ para todos os solos em conjunto. Dos coeficientes de correlação dos possíveis fatores influentes dos compartimentos solo-planta, o $\mathrm{Ca}$, o $\mathrm{Mg}$, o $\mathrm{Fe}$ e o Al não exerceram qualquer influência detectável na absorção do P. O Mn influenciou negativamente a absorção do $P$ pelas plantas nas áreas sobre os solos RLe $(p<0,01)$ e ABA. $(p<0,05)$. OKinfluenciou negativamente $(p<0,01)$ a absorção do $P$ no solo ABA. Em relação aos coeficientes de correlação e os níveis de significância dos possíveis fatores influentes da passagem do $P$ nos compartimentos planta-animal, o Ca não apresentou influência sobre a absorção do $\mathrm{P}$ pelo animal em nenhuma das áreas. O Fe afetou negativamente $(p<0,01)$ a absorção do $\mathrm{P}$ no solo $\mathrm{PHe}$ e o $\mathrm{Mn}$ mostrou efeito positivo $(p<0,01)$ sobre a absorção do $P$ no solo RLe. O comportamento diferenciado dos parâmetros influentes na passagem do fósforo na

Recibido: 7-2-07. Aceptado: 16-12-08.

\section{AdDitionAL KEYWORDS}

Absorption. Bovines. Minerals. Sanguineous serum.

cadeia solo-planta-animal sob condições de campo natural, é dependente do tipo de solo.

\section{SUMMARY}

A study was carried out to determine $P$ correlations with landscape characteristics and quality of the fodder plants in the soil-plant-animal system on three types of not disturbed soil, located in the region of Campanha-RS. There were sampled areas on Regolitic Eutrophic Neosol (RLe), Brown Grey Argisol (ABA) and Haplic Eutrophic Planosol $(\mathrm{PHe})$ soils during a year. The linear correlation between soil and plant $P$ was significant in autumn $(p<0.01)$ and winter $(p<0.05)$ for all soils. From soil-plant correlation coefficients among possible influent factors, was derived that $\mathrm{Ca}, \mathrm{Mg}, \mathrm{Fe}$ and $\mathrm{Al}$ do not affect $\mathrm{P}$ absortion. The $\mathrm{Mn}$ influenced negatively the $P$ absorption by plants on RLe $(p<0.01)$ and $A B A(p<0.05)$ soils. The $K$ negatively influenced $(p<0.01)$ the $P$ absorption in ABA soil. In relation to the possible influential factors on $P$ absortion in plant-animal system, Ca did not influenced the animal $\mathrm{P}$ absorption in none areas. The Fe negatively affected $(p<0.01)$ the absorption of $\mathrm{P}$ in $\mathrm{PHe}$ soil and $\mathrm{Mn}$ showed positive effect $(p<0.01)$ on the $\mathrm{P}$ absorption in PHe soil. The passage of $P$ through soil-plant-animal chain under field conditions is depending on soil type.

Arch. Zootec. 59 (228): 487-497. 2010. 


\section{INTRODUÇÃO}

Deficiências e desequilíbrios entre os minerais foram detectados em inúmeras regiões de todos os continentes, sendo a deficiência de fósforo no solo e na vegetação considerada a mais comum em todos os países estudados, inclusive no Brasil (Conrad et al., 1985; McDowell et al., 1993). Como resultado conseqüencial a deficiência de fósforo também é a mais comum em bovinos mantidos sob regime de pastejo e está relacionada à baixa produtividade destes, e de acordo com Tokarnia e Döbereiner (1973) é relacionada com enfermidades em algumas regiões do país.

A deficiência de nutrientes está relacionada à sua baixa disponibilidade na cadeia produtiva (produção primária), a qual depende de uma série de fatores, por vezes interdependentes, que influenciam sobremaneira o último elo da mesma, o animal. Alguns destes fatores não apresentam especificidade para determinado nutriente e, portanto, agem da mesma maneira para todos. Outros apresentam afinidade em maior ou menor escala com um determinado nutriente, afetando a sua disponibilidade em distintos graus. Entretanto, muitos destes fatores interagem entre si, podendo desta forma aumentar ou diminuir a disponibilidade do nutriente no seu trajeto, do primeiro ao último elo da cadeia produtiva. Por este motivo os aumentos dos índices de produtividade dos animais estão ligados à compreensão mais pormenorizada do mecanismo de transferência dos nutrientes no sistema solo-planta-animal.

De acordo com Mott (1974) e Pearson e Ison (1987) o complexo solo-planta-animal constitui um sistema de reciclagem de nutrientes, onde os nutrientes do solo encontram-se em equilíbrio com uma cadeia de resíduos, a qual representa um estado transitório de retorno de nutrientes para dentro do ciclo, através dos estágios: planta-animal.

Embora, de um modo geral, este fato seja verdadeiro, em função da complexidade dos fatores influentes e, que tanto a passagem, como o retorno de nutrientes ao início do ciclo não ocorre de forma homogênea entre os elos desta cadeia, deve-se enfocar cada nutriente em separado e, principalmente, aqueles que se encontrem menos disponíveis no sistema.

Este é o caso do fósforo que, em princípio, é considerado como um dos elementos que em nível mundial, encontra-se deficiente generalizadamente na maioria dos solos (Conrad et al., 1985; Ensminger, et al., 1990; NRC, 1996), apresentando teores totais num intervalo que varia entre 0,02 e $0,15 \%$ (Mengel e Kirby, 1982).

Dentre os minerais o fósforo é o elemento mais passível de se apresentar deficiente no solo, na vegetação e em animais em pastejo. Por isso é importante que este mineral seja alvo de um estudo mais detalhado, uma vez que este é, provavelmente, o mineral que desempenha o maior número de funções no organismo animal.

Apesar da existência de alguns estudos de levantamento dos teores de fósforo no solo e na vegetação de campo natural no estado do Rio Grande do Sul, estes são generalistas, não abrangem todas as estações do ano ou contemplam poucas épocas de observação. Aliado a isto, também o fato de que investigações sobre o comportamento deste elemento quando se considera a função solo-planta nas distintas épocas do ano são poucas no Brasil e, inexistentes em nível do Rio Grande do Sul, acrescenta maior importância a este tipo de estudo.

Partindo da premissa que a transferência de conhecimentos de região para região deve ser feita com cautela e, dada a complexidade da passagem do elemento fósforo desde o primeiro até o último elo da cadeia solo-planta-animal, estudos mais abrangentes devem ser feitos in loco.

O objetivo deste trabalho foi estudar a correlação do fósforo no solo, na vegetação e no soro sangüíneo dos animais em

Archivos de zootecnia vol. 59, núm. 228, p. 488. 
condições de campo natural, em três solos representativos da região da Campanha, RS, ao longo de oito épocas de observação, bem como determinar alguns fatores que influenciam a passagem do fósforo no sistema solo-planta-animal, a fim de se obter dados básicos que propiciem um melhor entendimento do comportamento deste elemento em áreas de campo natural, que possibilitarão futuras indicações de melhoramento destas áreas e o conseqüente incremento da produtividade animal.

\section{MATERIALE MÉTODOS}

\section{LOCALIZAÇÃO E CLIMA}

O experimento foi conduzido no Município de Bagé-RS, situado entre os paralelos de $30^{\circ} 30^{\prime} 30^{\prime \prime}$ e $31^{\circ} 56^{\prime} 00^{\prime \prime}$ e os meridianos de $54^{\circ} 30^{\prime} 0^{\prime \prime}$ e $55^{\circ} 30^{\prime} 00^{\prime \prime}$ a Oeste de Greenwich.

O clima dominante na região de acordo com a classificação de Köeppen-Geiger, é do tipo subtropical úmido, da classe $\mathrm{Cfa}$. onde: $\mathrm{C}=$ climas temperados, em que a temperatura média do mês mais frio é inferior a $18^{\circ} \mathrm{C}$ e superior a $-3^{\circ} \mathrm{C} ; \mathrm{f}=\mathrm{em}$ nenhum mês a precipitação é inferior a $60 \mathrm{~mm}$; $a=$ a temperatura média do mês mais quente é superior a $22^{\circ} \mathrm{C}$. As chuvas apresentam-se normalmente bem distribuídas durante o ano, podendo haver períodos secos, tanto no inverno como no verão. A precipitação média anual é de aproximadamente $1350 \mathrm{~mm}$, com variação de 20\% (Malufe Westphalen, 1994). A temperatura média anual é de $17,5^{\circ} \mathrm{C}$, sendo a média do mês mais quente (janeiro) de $24^{\circ} \mathrm{C}$ e a do mês mais frio (junho) de $12,5^{\circ} \mathrm{C}$. A formação de geadas pode ocorrer a partir de abril a novembro, sendo que as mesmas são mais freqüentes nos meses que vão de junho a agosto (Macedo, 1987).

\section{ÁREAEXPERIMENTAL}

Foram escolhidas três áreas de campo natural, não perturbado (virgem), mantidas sob pastejo, representativas da região, consideradas como de regular (área 1), boa (área 2) e de ótima (área 3) qualidade forrageira, classificadas por Macedo (1987), conforme o tipo de solo e paisagem, como segue. Área 1: solo Neossolo Regolítico eutrófico (RLe)/ Mata rala (MR) - vegetação campestre associada à mata arbustiva, com predominância de gramíneas (Paspalum sp.) e infestações de espécies desprezadas pelos animais, o relevo é fortemente ondulado com afloramento de rocha. Área 2: solo Argissolo Bruno-Acinzentado (ABA)/Campos mistos $(\mathrm{CM})$ - cobertura vegetal por volta de $60 \%$ formada por espécies de gramíneas, com predominância de Paspalum notatum e Axonopus affinis e incidência regular de leguminosas, o relevo é ondulado. Área 3: solo Planossolo Háplico eutrófico (PHe)/ Campos finos (CF) - cobertura vegetal acima de $80 \%$, formada por um grande número de espécies de gramíneas rizomatosas e estoloníferas, boa freqüência de leguminosas, relevo plano a suavemente ondulado. Dentre as espécies presentes destacam-se Andropogon lateralis, Desmodium spp, Fimbristylis diphyla.

\section{ANIMAIS EXPERIMENTAIS}

Em cada área experimental foram escolhidas aleatoriamente 12 novilhas (cruzamento indefinido Bos tauurs $\mathrm{x}$ Bos indicus), com peso médio de $250 \mathrm{~kg}$. Os animais permaneceram nos piquetes demarcados em cada área durante todo o período experimental e não receberam suplemento mineral. O método de pastejo utilizado foi o contínuo com lotação variável A taxa de lotação foi mantida em $05 \mathrm{UA} /$ ha durante o outono e inverno e 1,0 UA/ha na primavera e verão.

\section{Coletadeamostras}

A coleta de amostras foi efetuada durante um ano. O critério utilizado foi o início, meio e final de cada estação do ano, num total de oito coletas, durante o período experimental.

Foi escolhida uma propriedade em cada tipo de solo, na qual se demarcou um piquete, onde foram determinados quatro pontos fixos de coleta, para amostragem de solo e vegetação. 
O critério de escolha para determinar e distribuir estes quatro pontos na área experimental foi em função da topografia do terreno e dos pontos cardeais, de modo a garantir a representatividade da área e que a amostragem fosse realizada sempre no mesmo lugar. A partir desses pontos, contando-se 20 metros, determinou-se um ponto imaginário em torno do qual foram coletadas as amostras (figura 1).

\section{Solo}

As amostras de solo foram coletadas a uma profundidade de $15 \mathrm{~cm}$, com trado inoxidável. Foi obtida uma amostra composta de 6 subamostras, totalizando 4 amostras compostas por ponto fixo num total de 16 amostras por coleta, para determinação dos teores de fósforo cálcio, potássio, magnésio, alumínio, ferro e manganês e valores de $\mathrm{pH}$ no solo (figura 1), segundo a metodologia proposta por Tedesco et al. (1985). Foi analisado o $\mathrm{P}$ disponível, que envolve o orgânico e inorgânico).

\section{Planta}

As amostras da vegetação, em número de 16 amostras compostas por época, foram coletadas da mesma maneira que as de solo (figura 1). $\mathrm{O}$ corte foi feito simulando a altura do pastejo dos animais evitando-se a coleta de espécies desprezadas pelos animais. Foram analisados os teores de fósforo segundo a metodologia proposta por Tedesco et al. (1985). A vegetação analisada continha espécies nos estádios vegetativo e de florescimento.

\section{Sangue}

As amostras foram coletadas através da punção da veia jugular e processadas, posteriormente, para a obtenção do soro sangüíneo (Dayrell et al., 1973). A análise da concentração de fósforo no soro sanguíneo foi realizada segundo Fick et al. (1980).

\section{ANÁLISE ESTATÍSTICA}

Para a análise dos dados foi utilizado um fatorial AxB, no delineamento completa- mente casualizado, com quatro repetições Os fatores A (solos) e B (épocas), constaram de três e oito níveis, respectivamente.

Os dados foram analisados através de uma análise de correlação parcial para as varáveis $\mathrm{P}$ no solo, $\mathrm{P}$ na planta e $\mathrm{P}$ no sangue. A análise foi feita para o total de observações e para cada uma das estações do ano.

Também foi realizada uma análise de correlação linear simples entre as três variáveis, fósforo no solo (X1), fósforo na planta (X2) e fósforo nos animais (X3), tomadas duas a duas, para todos os solos em todas as épocas. A análise foi feita para o total de observações e para cada uma das estações do ano. Correlações parciais entre estas mesmas variáveis complementaram o estudo.

As análises estatísticas foram realizadas utilizando-se o Sistema de Análise Estatística para Microcomputadores Sanest (Zonta e Machado, 1993).

Os dados referentes aos doze animais

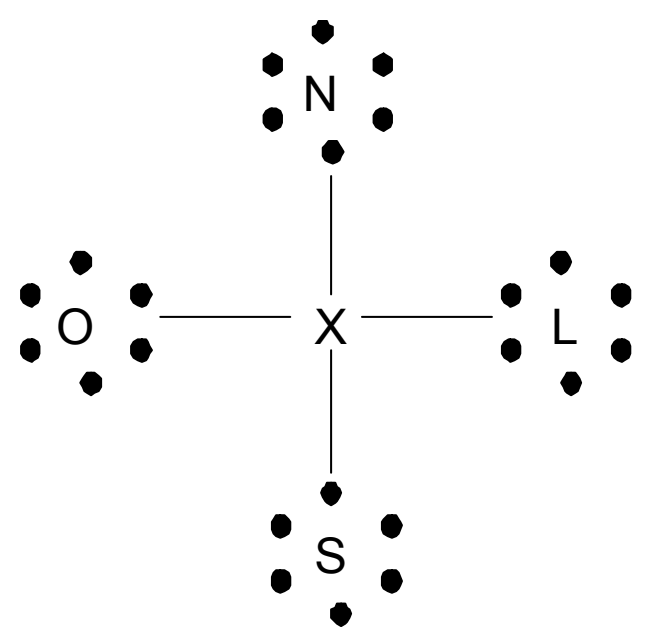

Ponto de coleta de subamostra $X$ Ponto fixo

Figura I. Esquema do sistema de amostragem utilizado no campo. (Sampling procedure used in the field). 
foram ordenados e divididos em três grupos de quatro animais, sendo cada um dos grupos compostos como segue: 1- grupo de animais com maiores teores de fósforo no sangue; 2- grupo de animais com teores intermediários de fósforo no sangue; 3 - grupo de animais com menores teores de fósforo no sangue. Após sorteou-se aleatoriamente, um animal de cada grupo para um ponto fixo de coleta de solo e vegetação, formando-se quatro grupos de três animais por ponto fixo, de modo que estas médias participassem das análises estatísticas.

Para ambos os fatores, solos e épocas, os dados foram agrupados de acordo com as quatro estações do ano pelas datas de coleta no campo: na primavera (novembro e dezembro), no verão (fevereiro e março), no outono (maio e junho) e no inverno (agosto e setembro) com a finalidade de melhor comparar estes resultados obtidos com trabalhos previamente consultados.

\section{RESULTADOSEDISCUSSÃO}

Os teores médios de fósforo observados nos solos Neossolo Regolítico eutrófico, Planossolo Háplico eutrófico e Argissolo Bruno-Acinzentado foram respectivamente 7,$0 ; 5,0$ e $3,1 \mathrm{mg} \cdot \mathrm{dm}^{3}$, sendo que o Neossolo Regolítico eutrófico mostrou-se significativamente superior aos demais $(\mathrm{p}<0,05)$ (tabela I). Constatou-se que esses solos apresentam baixos teores médios de fósforo disponível à vegetação do campo natural em todas as estações do ano. O teor mais elevado de fósforo no solo Neossolo Regolítico eutrófico $\left(7,07 \mathrm{mg} \cdot \mathrm{dm}^{3}\right)$ está associado ao fato deste estar ainda em processo de formação (seqüência de horizontes $\mathrm{A} / \mathrm{R}$ ou $\mathrm{A} / \mathrm{C}$ ), podendo ser considerado como um solo jovem, o que possibilita que este apresente uma maior concentração de determinados nutrientes em relação aos solos Argissolo Bruno-Acinzentado e Planossolo Háplico eutrófico, que são considerados solos mais velhos, ou seja, que sofreram um processo de intemperização
Tabela I. Comparações entre fósforo no solo $(S)$, na planta $(P)$ e no animal $(A)$. (Comparisons among soil $(\mathrm{S})$, plant $(\mathrm{P})$, and animal $(\mathrm{A})$ phosphorus).

\begin{tabular}{|c|c|c|c|}
\hline Nome & $S$ & $P$ & A \\
\hline Neossolo Regolítico eutrófico & $7,0^{\mathrm{a}}$ & 1,02 & 3,834 \\
\hline Planossolo Háplico eutrófico & $5,0^{\mathrm{b}}$ & 0,90 & 3,913 \\
\hline Argissolo Bruno-Acinzentado & $3,1^{c}$ & 1,08 & 4,446 \\
\hline
\end{tabular}

maior, o que lhes possibilitou alcançar seu desenvolvimento completo, e conseqüentemente, apresenta uma menor quantidade de nutrientes disponíveis às plantas ao longo dos anos. A textura do solo Neossolo Regolítico eutrófico é outro fator que possivelmente pode explicar o seu teor mais elevado de fósforo. Solos arenosos normalmente apresentam frações de material mais grosseiro fixando menos fósforo em decorrência de sua menor área superficial adsorvente em comparação com os solos de textura mais argilosa (Jorge, 1983), como é o caso dos solos Argissolo Bruno-Acinzentado e Planossolo Háplico eutrófico.

Na planta os teores médios encontrados foram 1,02; 0,90 e 1,08 g. $\mathrm{kg}^{-1}$ na MS (tabela I) para os solos Neossolo Regolítico eutrófico, Planossolo Háplico eutrófico e Argissolo Bruno-Acinzentado, sendo que houve interação entre solo e época do ano (tabela II). Verifica-se que os valores médios de fósforo nas pastagens naturais da região estudada em base de matéria seca, são muito baixos, não atendendo na maioria das vezes os níveis dietéticos mínimos propostos pelo NRC (1996) de 1,20, g. $\mathrm{kg}^{-1}$ para todas as categorias de animais. Observa-se que não houve relação entre os teores médios de $\mathrm{P}$ observados nos solos e os teores médios encontrados na vegetação. Como os teores de $\mathrm{P}$ disponíveis nos ecossistemas naturais são baixos, diversos mecanismos sãso uti- 
Tabela II. Teores médios de fósforo $\left(\mathrm{g} . \mathrm{kg}^{-1}\right)$ nas plantas forrageiras dos solos Neossolo Regolítico Eutrófico (RLe), Argissolo Bruno-Acinzentado (ABA)e Planossolo Háplico eutrófico (PHe) em cada coleta e estação do ano. (Average amount of phosphorus (g. $\mathrm{kg}^{-1}$ ) in forage plants on Regolitic Eutrophic Neosol (RLe), Brown Grey Argisol (ABA) and Haplic Eutrophic Planosol (PHe) soils by sample and season).

\begin{tabular}{lccccccrr}
\hline & \multicolumn{2}{c}{ Primavera } & \multicolumn{2}{c}{ Verão } & \multicolumn{2}{c}{ Outono } & \multicolumn{2}{c}{ Inverno } \\
Solos & nov & dez & fev & mar & maio & jun & ago & set \\
\hline RLe & $1,30^{\mathrm{a}}$ & $1,25^{\mathrm{a}}$ & $1,05^{\mathrm{b}}$ & $1,05^{\mathrm{b}}$ & $0,97^{\mathrm{a}}$ & $0,90^{\mathrm{a}}$ & $0,80^{\mathrm{a}}$ & $0,82^{\mathrm{a}}$ \\
$\mathrm{ABA}$ & $1,40^{\mathrm{a}}$ & $1,30^{\mathrm{a}}$ & $1,32^{\mathrm{a}}$ & $1,30^{\mathrm{a}}$ & $0,92^{\mathrm{a}}$ & $0,82^{\mathrm{a}}$ & $0,77^{\mathrm{a}}$ & $0,82^{\mathrm{a}}$ \\
PHe & $1,00^{\mathrm{b}}$ & $0,82^{\mathrm{b}}$ & $1,02^{\mathrm{b}}$ & $0,97^{\mathrm{b}}$ & $0,87^{\mathrm{a}}$ & $0,82^{\mathrm{a}}$ & $0,82^{\mathrm{a}}$ & $0,80^{\mathrm{a}}$ \\
\hline
\end{tabular}

Médias seguidas de mesma letra minúscula, nas colunas, não diferiram $(p<0,05)$ entre si pelo Teste de Duncan.

lizados pelas plantas e organismos adaptados para aumentar a eficiência de absorção de P (Rhaghothama, 1999);

No soro sangüíneo os teores médios verificados foram 3,834; 3,913 e 4,446 mg/ $100 \mathrm{ml}$ respectivamente para os solos Neossolo Regolítico eutrófico,, Planossolo Háplico eutrófico (PHe) e Argissolo BrunoAcinzentado (tabela I), também houve interação entre solo e época do ano (tabela III).Considerando que o número total de amostras de soro de sangue com níveis de fósforo sérico dentro do limite de normalidade durante todo o período experimental, em todos os solos, foi de $50 \%$, infere-se que os animais mantidos em regime de pastejo extensivo contínuo e sem suplementação mineral, na região da Campanha-RS, embora ocorrendo níveis normais, apresentam baixos níveis de fósforo no soro de sangue.

Procedeu-se uma análise de correlação linear simples dos teores de fósforo com o pH e alguns elementos minerais que sabidamente (Malavolta, 1980; Mengel e Kirby, 1982; Van Raij, 1991) afetam o teor de fósforo disponível às plantas (tabela IV). Observou-se que quanto ao efeito do $\mathrm{pH}$ houve uma correlação positiva e estatisticamente significativa $(\mathrm{p}<0,05)$ no Planossolo Háplico eutrófico (PHe), enquanto que nos outros dois solos estudados o efeito do pH não foi significativo. Em relação

Tabela III. Teores médios de fósforo $\left(\mathrm{mg} 100 \mathrm{ml}^{-1}\right)$ no soro sangüineo de animais sobre os solos Neossolo Regolítico Eutrófico (RLe), Argissolo Bruno-Acinzentado (ABA) e Planossolo Háplico eutrófico (PHe) em cada coleta e estação do ano. (Average amount of phosphorus (mg.100 ml-1) in blood serum of animals on Regolitic Eutrophic Neosol (RLe), Brown Grey Argisol (ABA) and Haplic Eutrophic Planosol (PHe) soils by sample and season).

\begin{tabular}{lcccccccr}
\hline & \multicolumn{2}{c}{ Primavera } & \multicolumn{2}{c}{ Verão } & \multicolumn{2}{c}{ Outono } & \multicolumn{2}{c}{ Inverno } \\
Solos & nov & dez & fev & mar & maio & jun & ago & set \\
\hline RLe & $3,817^{\mathrm{a}}$ & $3,723^{\mathrm{b}}$ & $3,651^{\mathrm{c}}$ & $3,726^{\mathrm{b}}$ & $4,691^{\mathrm{a}}$ & $3,885^{\mathrm{a}}$ & $3,107^{\mathrm{b}}$ & $4,075^{\mathrm{b}}$ \\
ABA & $3,923^{\mathrm{a}}$ & $5,031^{\mathrm{a}}$ & $4,700^{\mathrm{a}}$ & $4,109^{\mathrm{b}}$ & $4,236^{\mathrm{b}}$ & $4,309^{\mathrm{a}}$ & $3,971^{\mathrm{a}}$ & $5,289^{\mathrm{a}}$ \\
PHe & $4,077^{\mathrm{a}}$ & $4,863^{\mathrm{a}}$ & $4,082^{\mathrm{b}}$ & $4,532^{\mathrm{a}}$ & $3,470^{\mathrm{c}}$ & $3,984^{\mathrm{a}}$ & $2,926^{\mathrm{b}}$ & $3,377^{\mathrm{c}}$ \\
\hline
\end{tabular}

Médias seguidas de mesma letra minúscula, nas colunas, não diferiram $(p<0,05)$ entre si pelo Teste de Duncan.

Archivos de zootecnia vol. 59, núm. 228, p. 492. 
aos elementos minerais, no solo Neossolo Regolítico eutrófico observou-se uma correlação negativa e altamente significati$\mathrm{va}(\mathrm{p}<0,01)$ entre o fósforo e o ferro, já para o solo Argissolo Bruno-Acinzentado esta correlação negativa foi somente significativa $(p<0,05)$. O cálcio, o alumínio e o manganês não apresentaram uma correlação significativa com o fósforo extraível em todas as épocas estudadas nestes solos. No Planossolo Háplico eutrófico, o teor de fósforo extraível apresentou correlação negativa e altamente significativa $(\mathrm{p}<0,01)$ com o alumínio, sendo que para os demais elementos esta correlação não apresentou efeito significativo.

No caso do cálcio a não significância das correlações deve-se ao valor do $\mathrm{pH}$ encontrado nos três solos, uma vez que, mesmo as grandes quantidades de cálcio (três vezes mais) encontradas no Planossolo Háplico eutrófico, não afetaram o teor de fósforo extraível. Estas observações estão de acordo com as indicações de Malavolta (1980), segundo o qual a fixação dos fosfatos pelo cálcio ocorre a partir de $\mathrm{pH}$ maior do que 6,0, e nos três solos estudados em nenhuma época detectou-se um $\mathrm{pH}$ superior a este valor.

As significâncias negativas encontradas, do fósforo em relação ao ferro, nos solos Neossolo Regolítico eutrófico e Argissolo Bruno-Acinzentado devem-se além do teor de ferro destes dois solos, que foram em média $20 \%$ maior que no Planossolo Háplico eutrófico, também ao $\mathrm{pH}$ bastante ácido dos dois primeiros solos, que propiciou uma maior complexação dos fosfatos.

Quando se considera o fósforo em relação ao alumínio, observa-se que embora os solos Neossolo Regolítico eutrófico e Argissolo Bruno-Acinzentado não tenham apresentado correlação significativa e, ao contrário detectou-se um efeito altamente significativo da mesma correlação no Planossolo Háplico eutrófico, nota-se que o solo Neossolo Regolítico eutrófico apresentou teores de alumínio três vezes maiores e o Argissolo Bruno-Acinzentado seis vezes maiores que o Planossolo Háplico eutrófico. Neste caso não é encontrado na literatura uma explicação plausível para tal comportamento quando se considera a quantidade deste elemento, entretanto a maior fixação dos fosfatos pelo alumínio ocorre segundo Malavolta (1980) a partir de um valor de $\mathrm{pH}$ acima de 5,0. Desta forma, apesar de que o $\mathrm{pH}$ quando relacionado ao teor de fósforo extraível não tenha apresentado efeito significativo nos solos Neossolo Regolítico eutrófico e Argissolo Bruno-Acinzentado, e o valor médio do $\mathrm{pH}$

Tabela IV. Coeficientes de correlação entre o teor médio de fósforo extraível com o valor de pH e os teores médios anuais de alguns elementos influentes no solo. (Correlation coefficients between the average amount of extracted phosphorus with the $\mathrm{pH}$ value and the average amount of some influent elements in the soil).

\begin{tabular}{|c|c|c|c|c|c|c|}
\hline & \multicolumn{2}{|c|}{$\begin{array}{c}\text { Neossolo } \\
\text { Regolítico eutrófico }\end{array}$} & \multicolumn{2}{|c|}{$\begin{array}{c}\text { Argissolo } \\
\text { Bruno-Acinzentado }\end{array}$} & \multicolumn{2}{|c|}{$\begin{array}{c}\text { Planossolo } \\
\text { Háplico eutrófico }\end{array}$} \\
\hline & valor & relação & valor & relação & valor & relação \\
\hline $\mathrm{pH}$ & 4,89 & $-0,291^{\mathrm{ns}}$ & 4,84 & $-0,076^{\mathrm{ns}}$ & 5,12 & $0,390^{*}$ \\
\hline $\mathrm{Ca}(\mathrm{me} / \mathrm{dl})$ & 2,640 & $-0,243^{\text {ns }}$ & 2,920 & $0,134^{\mathrm{ns}}$ & 9,580 & $0,296^{\mathrm{ns}}$ \\
\hline $\mathrm{Fe}(\%)$ & 0,350 & $-0,543^{* *}$ & 0,376 & $-0,407^{*}$ & 0,284 & $-0,063^{n s}$ \\
\hline $\mathrm{Al}(\mathrm{me} / \mathrm{dl})$ & 0,576 & $-0,228^{\text {ns }}$ & 0,818 & $-0,076^{\text {ns }}$ & 0,132 & $-0,519^{* *}$ \\
\hline Mn (ppm) & 58,80 & $-0,193^{\text {ns }}$ & 37,60 & $-0,252^{\text {ns }}$ & 80,18 & $0,221^{\mathrm{ns}}$ \\
\hline
\end{tabular}

ns: não significativo. ${ }^{*} p<0,05 ;{ }^{* *} p<0,01$. 
para estes dois solos ficou abaixo de 5,0, justifica-se a não correlação do alumínio com o fósforo extraível nestes solos. A significância da correlação negativa do alumínio com o fósforo no Planossolo Háplico eutrófico também é justificada pelo valor do $\mathrm{pH}$ que foi acima de 5,0, embora os teores de alumínio neste solo sejam menores.

Não foi verificada significância na relação do manganês com fósforo extraível em nenhum dos solos estudados. No Planossolo Háplico eutrófico onde se verificou a maior concentração de manganês, possivelmente o $\mathrm{pH}$ mais alcalino não propiciou a complexação dos fosfatos por este elemento. Nos outros dois solos mais ácidos possivelmente tenha sido favorecida a conversão do manganês trocável e da solução do solo em formas de valência mais elevada $\left(\mathrm{Mn}^{+3}\right.$ e $\left.\mathrm{Mn}^{+4}\right)$, estas consideradas muito insolúveis (Mengel e Kirby, 1982), evitando assim a complexação dos fosfatos.

Quanto às correlações lineares calculadas para fósforo no solo $\mathrm{x}$ fósforo na planta $(\mathrm{r}=-0,184)$, fósforo no solo $\mathrm{x}$ fósforo no animal $(r=-0,155)$ e fósforo na planta $x$ fósforo no animal $(r=0,167)$ estas não foram significativas, ao nível de 5\% .

$\mathrm{Na}$ literatura consultada praticamente não foram encontrados trabalhos que estudassem correlação linear no sistema solo-planta-animal referentemente ao fósforo; constata-se, entretanto, que os resultados obtidos neste estudo contrastam com as observações de Sousa et al. (1979). Esses autores encontraram uma correlação linear positiva e estatisticamente significativa $(\mathrm{p}<0,01)$ entre o fósforo no solo $\mathrm{x}$ fósforo na planta quando avaliaram as amostras de seis áreas experimentais em cinco diferentes municípios, em duas épocas (chuvosa e seca). O presente estudo determinou um comportamento oposto, ou seja, a relação não foi significativa e a tendência foi negativa, quando se considera as três áreas como um todo.

No que diz respeito à correlação linear entre fósforo na planta $\mathrm{x}$ fósforo no tecido ósseo, Sousa et al. (1979) não encontraram significância e sim uma tendência a ser negativa, o que contrapõe-se aos resultados observado neste trabalho no qual também não foi observada significância, porém, em se considerando tendência, esta foi positiva. Estes resultados divergentes podem haver ocorrido em função de que o parâmetro de comparação nos animais tenha sido diferente nos dois trabalhos, uma vez que, no presente estudo o sangue foi o material utilizado, e no de Sousa et al. (1979), o tecido ósseo.

$\mathrm{Na}$ busca de uma informação mais detalhada resolveu-se analisar as correlações lineares entre estas três variáveis em cada uma das estações do ano. Dentre as correlações lineares simples estudadas somente fósforo no solo $\mathrm{x}$ fósforo na planta apresentou significância no outono $(p<0,01)$ e no inverno $(\mathrm{p}<0,05)$ para todos os solos em conjunto; como as correlações foram positivas, o aumento destas variáveis é concordante, ou seja, o aumento nos teores de fósforo no solo ocorridos durante o outono e o inverno foi acompanhado por aumento nos teores deste mineral na planta. Isto demonstra a existência de uma dependência no sistema solo-planta, que possibilita a disponibilidade do referido mineral mesmo que em quantidades nem sempre suficientes para atender as exigências nutricionais dos animais em pastejo na região objeto de estudo deste trabalho.

No estudo das correlações parciais para os solos em conjunto e considerando cada uma das estações do ano em separado, por ocasião da retirada do efeito do solo (X1) entre $\mathrm{X} 2$ e X3 e da retirada do efeito da planta (X2) entre X1 e X3, pode-se verificar que os coeficientes de correlação obtidos diferem bastante daqueles das correlações lineares simples e, não foram significativos em nenhuma estação do ano. Verifica-se, portanto, que a passagem do fósforo no sistema solo-planta-animal depende do tipo de solo e do estádio de desenvolvimento 
das plantas, relacionado com a estação do ano, logo os teores de fósforo no soro sangüíneo dependem das condições edafoclimáticas.

Em função destes resultados procurouse averiguar o efeito do tipo de solo (área) em separado e em cada estação do ano.

Constatou-se que as significâncias observadas no período outono-inverno na relação fósforo no solo $\mathrm{x}$ fósforo na planta deveu-se ao solo Neossolo Regolítico eutrófico no outono $(\mathrm{r}=0,85 ; \mathrm{p}<0,01)$ e no inverno $(r=0,72 ; p<0,05)$, bem como ao solo Argissolo Bruno-Acinzentado no inverno $(\mathrm{r}=0,73 ; \mathrm{p}<0,05)$. Na primavera, também se observou uma relação significativa $(\mathrm{r}=0,74$; $\mathrm{p}<0,05)$ entre o fósforo no solo $\mathrm{x}$ fósforo na planta na área do solo Argissolo BrunoAcinzentado.

Enquanto que no Planossolo Háplico eutrófico não foi observada relação entre os três compartimentos da função solo-plantaanimal em nenhuma época, na primavera detectou-se significância das relações fósforo no solo $\mathrm{x}$ fósforo no soro $(\mathrm{r}=0,93$; $\mathrm{p}<0,01)$ e fósforo na planta $\mathrm{x}$ fósforo no soro $(\mathrm{r}=0,76 ; \mathrm{p}<0,05)$ no solo Neossolo Regolítico eutrófico.

Os resultados destas análises sugerem a existência de uma relação fortemente dependente do tipo de solo (área) e da estação climática na passagem do fósforo pelo sistema solo-planta-animal, a qual não foi constatada nas primeiras análises em virtude de que as mesmas relacionaram os três solos como um todo.

Desta forma, no caso do fósforo, é necessário aprofundar mais os estudos da dependência deste elemento no sistema solo-planta-animal considerando cada área (tipo de solo) e estação do ano em separado, através de um maior número de repetições por estação climática.

Também no âmbito deste estudo procurou-se também identificar os fatores influentes na passagem do fósforo no sistema solo-planta-animal, individualmente.

Na tabela IV encontram-se relacionados os coeficientes de correlação dos possíveis fatores influentes dos compartimentos soloplanta com as respectivas significâncias.

Observa-se que o fator $\mathrm{pH}$ influenciou negativamente a absorção do fósforo das plantas somente no solo Argissolo BrunoAcinzentado. O cálcio, o magnésio, o ferro e o alumínio não exerceram qualquer influência detectável na absorção do fósforo (tabela V).

O manganês influenciou negativamente a absorção do fósforo pelas plantas nas áreas sobre os solos Neossolo Regolítico eutrófico $(p<0,01)$ e Argissolo BrunoAcinzentado $(p<0,05)$, fato este que deve estar relacionado com a acidez do solo, embora a relação $\mathrm{pH} x$ fósforo não tenha acusado significância para o solo Neossolo Regolítico eutrófico. Outro fato que corrobora esta afirmativa é que no solo Planossolo Háplico eutrófico, menos ácido, não houve correlação significativa.

$\mathrm{O}$ potássio influenciou negativamente $(\mathrm{p}<0,01)$ a absorção do fósforo no solo Argissolo Bruno-Acinzentado, possi-

Tabela V. Relação de os teores médios anuais de fósforo na planta com o pH e os teores médios anuais de alguns elementos no solo que influenciam a absorção pelas plantas. (Average annual $\mathrm{P}$ contents in plant in relation with the $\mathrm{pH}$ and average amounts of some soil elements which influence the absorption by the plants).

\begin{tabular}{lccc}
\hline & NRe & AB-A & PHe \\
\hline $\mathrm{pH}$ & $-0,255^{\text {ns }}$ & $-0,393^{*}$ & $0,240^{\text {ns }}$ \\
$\mathrm{Ca}\left(\mathrm{cmol} / \mathrm{dm}^{3}\right)$ & $-0,186^{\text {ns }}$ & $0,293^{\text {ns }}$ & $0,166^{\text {ns }}$ \\
$\mathrm{Fe}\left(\mathrm{mg} / \mathrm{dm}^{3}\right)$ & $-0,143^{\text {ns }}$ & $0,153^{\text {ns }}$ & $-0,291^{\text {ns }}$ \\
$\mathrm{Al}\left(\mathrm{cmol} / \mathrm{dm}^{3}\right)$ & $0,0151^{\text {ns }}$ & $0,062^{\text {ns }}$ & $0,013^{\text {ns }}$ \\
$\mathrm{Mn}(\mathrm{ppm})$ & $-0,573^{* *}$ & $-0,373^{*}$ & $-0,259^{\text {ns }}$ \\
$\mathrm{Mg}(\mathrm{me} / \mathrm{dl})$ & $-0,226^{\text {ns }}$ & $-0,092^{\text {ns }}$ & $-0,208^{\text {ns }}$ \\
$\mathrm{K}(\mathrm{ppm})$ & $-0,259^{\text {ns }}$ & $-0,620^{* *}$ & $-0,080^{\text {ns }}$
\end{tabular}

NRe: Neossolo Regolítico eutrófico; AB-A: Argissolo Bruno-Acinzentado; PHe: Planossolo Háplico eutrófico.

ns: não significativo. ${ }^{*} p<0,05 ;{ }^{* *} p<0,01$. 
velmente devido à inibição da absorção do magnésio pelas plantas naquela área, uma vez que o magnésio é o carregador do fósforo no processo de absorção e concorre com o potássio pelos sítios de absorção na planta (Malavolta, 1980; Mengel e Kirby, 1982; Jorge, 1983).

Na tabela VI encontram-se os coeficientes de correlação e os níveis de significância dos possíveis fatores influentes da passagem do fósforo nos compartimentos plantaanimal.

Observa-se que o cálcio não apresentou influência sobre a absorção do fósforo pelo animal em nenhuma das áreas experimentais. $\mathrm{O}$ ferro afetou negativamente $(\mathrm{p}<0,01)$ a absorção do fósforo somente no solo Planossolo Háplico eutrófico. Inesperadamente, o manganês mostrou efeito positivo $(p<0,01)$ sobre a absorção do fósforo no solo Neossolo Regolítico eutrófico, o que se justifica apenas pelo fato de que na vegetação deste solo o teor médio deste elemento era $20,3 \%$ menor que nas outras duas épocas.

Os distintos comportamentos dos fatores influentes sobre a passagem do fósforo por cada elo da cadeia solo-planta-animal corroboram mais uma vez as observações feitas no presente estudo de que o fósforo neste sistema, sob condições de campo natural, é

\section{BIBLIOGRAFIA}

Conrad, J.H., McDowell, L.R., Ellis, G.L. e Loosli, J.K. 1985. Minerais para ruminantes em pastejo em regiões tropicais. Departamento de Ciência Animal; Centro de Agricultura Tropical, Universidade da Florida e Agência Americana para o Desenvolvimento Internacional. Gainesville. 91 pp.

Dayrell, M.S., Lopes, H.O.S., Sampaio, I.B.M. e Döbereiner, J. 1973. Fatores a serem considerados na interpretação de valores analíticos de fósforo inorgânico no soro sangüíneo de bovinos. Pesqui. Agropecu. Bras., 8: 43-47.

Ensminger, M.E., Oldfield, J.E. and Heinemann, W.W. 1990. Feeds and Nutrition. $2^{\text {nd }}$ ed. The Ensminger Publishing Company. Clovis. 1544 pp.
Tabela VI. Relação entre os teores médios anuais de fósforo no soro sangüíneo dos animais experimentais e os teores médios anuais de alguns elementos nas plantas que influenciam a absorção pelo animal. (Average annual $\mathrm{P}$ contents in the experimental animals in relation with some plant elements which influence the absorption by the animal).

\begin{tabular}{lccc}
\hline & $\mathrm{NRe}$ & $\mathrm{AB}-\mathrm{A}$ & $\mathrm{PHe}$ \\
\hline $\mathrm{Ca}(\%)$ & $-0,3256^{\mathrm{ns}}$ & $-0,0204^{\mathrm{ns}}$ & $0,1998^{\text {ns }}$ \\
$\mathrm{Fe}(\mathrm{mg} / \mathrm{kg})$ & $-0,1179^{\mathrm{ns}}$ & $0,0877^{\mathrm{ns}}$ & $-0,5959^{* *}$ \\
$\mathrm{Mn}(\mathrm{mg} / \mathrm{kg})$ & $0,5849^{* *}$ & $0,2105^{\mathrm{ns}}$ & $-0,2113^{\text {ns }}$
\end{tabular}

NRe: Neossolo Regolítico eutrófico; $A B-A$ : Argissolo Bruno-Acinzentado; PHe: Planossolo Háplico eutrófico.

ns: não significativo. ${ }^{*} p<0,05 ;{ }^{* *} p<0,01$.

extremamente dependente do tipo de solo.

\section{CONCLUSÕES}

O comportamento diferenciado dos parâmetros influentes na passagem do $\mathrm{P}$ na cadeia solo-planta-animal sob condições de campo natural, é dependente do tipo de solo.

A vegetação diretamente relacionada com o tipo de solo e as estações climáticas alteram a passagem do fósforo pelo sistema solo-planta-animal.

Fick, R.K., McDowell, L.R., Miles, P.H., Wilkinson, N.S. e Conrad, J.H. 1980. Métodos de análise de minerais em tecidos de animais e plantas. $2^{a}$ ed. pp. 35-58.

Jorge, J.A. 1983. Solo, manejo e adubação. $2^{a}$ ed. rev. e ampl. Nobel. São Paulo. 315 pp.

Macedo, W. 1987. Levantamento de reconhecimento dos solos do município de Bagé, RS. Em: Coletânea das Pesquisas Forrageiras. Empresa Brasileira de Pesquisa Agropecuária Centro Nacional de Pesquisa de Ovinos. EmbrapaCnpo. Bagé, RS. Documentos, 3. 1: 285-338.

Malavolta, E.A. 1980. Absorção de elementos pelas raízes. Em: Elementos de nutrição mineral de plantas. Editora Agronômica Ceres.

Archivos de zootecnia vol. 59, núm. 228, p. 496. 


\section{CORRELAÇÃO DO FÓSFORO SOLO-PLANTA-ANIMAL NA REGIÃO DA CAMPANHA-RS}

Piracicaba. pp. 45-79.

Maluf, J.R.T. e Westphalen, S.L. 1994. Macro zoneamento agroecológico e econômico do Rio Grande do Sul. Secretaria da Agricultura e Abastecimento. Centro Nacional de Pesquisa de Trigo. Porto Alegre. 307 pp.

McDowell, L.R., Conrad, J.H. and Glen Hembry, F. 1993. Minerals for grazing ruminants in tropical regions. $2^{\text {nd }}$ Edition U.S. Agency for International Development and Caribbean Basin Advisory Group. Library of Congress. Gainesville, FL. EEUU. 77 pp.

Mengel, K. and Kirby, E. 1982. Principles of plant nutrition. $3^{\text {rd }}$ ed. International Potash Institute. Berna. Switzerland. $655 \mathrm{pp}$.

Mott, G.O. 1974. Nutrient recycling in pastures. In: Mays, D.A. (ed.). Forage fertilization. ASACSSA-SSSA. cap.15. Madison. pp. 323-329.

NRC. 1996. Nutrient requeriments of beef cattle. 7 . Ed. rev. National Academy Press. Washington D.C. 242 pp.

Pearson, C.J. and Ison, R.L. 1987. Agronomy of grassland systems. Cambridge University Press. New York. 169 pp.
Sousa, J.C. de., Conrad, J.H., Blue, W.G. e McDowell, L.R. 1979. Inter-relações entre minerais no solo, plantas forrageiras e tecido animal. I. Cálcio e fósforo. Pesqui. Agropecu. Bras., 14: 387-95.

Rhaghothama, K.G. 1999. Phosphate acquisition. Annual review of plants physiology and plant molecular biology. Stanford, v. 50. pp. 665-693.

Tedesco, M.J., Volkweiss, S.J. e Bohnen, H. 1985. Análises de solo, planta e outros materiais. UFRGS/Faculdade de Agronomia. Departamento de Solos. Porto Alegre. Boletim Técnico, 5. 95 pp.

Tokarnia, C.H. and Döbereiner, J. 1973. Diseases caused by mineral deficiences in cattle raised under range conditions in Brazil. A review. Pesqui. Agropecu. Bras., 8 (Suppl): 1-6.

Van Raij, B. 1991. Fertilidade do solo e adubação. Editora Agronômica Ceres Ltda./Associação Brasileira para Pesquisa da Potassa e do Fosfato. Piracicaba. 343 pp.

Zonta, E.P. e Machado, A.D. 1993. Sanest, sistema de análise estatística para microcomputadores. Ciagri/Esalq, USP. Piracicaba. 138 pp. 